\title{
شعر الزهد بين الإمام الشافعي وأبي العتاهية دراسة مقارنة
}

\section{Sekou KOUYATE}

King Saud University

jelifama@gmail.com

\section{الملخص}

يهدف البحث إلى المقارنة بين الشاعرين من حيث العوامل الاجتماعية، الدينية، الثقافية والاقتصادية، والنفسية، ثم يتضمن الحديث عن المضامين الشعرية المتشاهة لدى كلا الشاعرين، في إطار شعر الزهد.

استخدم الباحث منهج المدرسة الفرنسية، التي تجرى فيها المقارنة بين الآداب التي يرتبط بعضها ببعض على أساس التأثّر والثأثير .

وكان من أبرز نتائج الدراسة أن أبا العتاهية قد تأثّر بالشافعي في بعض مضامين شعره الزهدي، لكنه ابتدع فيها

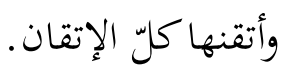

الكلمات المفتاحية : شعر الزهد، الإمام الشافعي، أبو العتاهية، الأدب المقارن.

\section{المقدمة}

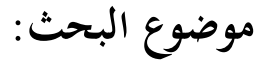

يقوم البحث على مقارنة تطبيقية بين الشاعر الإمام الشافعي، وأبي العتاهية في إطار الشعر الزهدي، وقد اقتضت طبيعة البحث أن يتكون من مقدمة، ومبحثين، وتناولت المقدمة موضوع البحث وخطته، ومنهجه، وتساؤلاته، وتناول المبحث الأول نبذة عن حياة الشاعرين، وجُعل المبحث الثاني لتحليل المضامين الزهدية من خلال النماذج المختارة لكل . وأما منهج الدراسة، فالدراسة تقوم على أساس المدرسة الفرنسية، التي تجرى فيها المقارنة بين الآداب التي يرتبط بعضها ببعض على أساس من العلاقة، أي أن يكون هناك مؤثّر ومتأثّّر ، وناقل ومنقول عنه. 
وأما السؤال الأساسي الذي تبحث عنه الدراسة هو : هل تأثر أبو العتاهية في شعره الزهدي بالإمام الشافعي؟

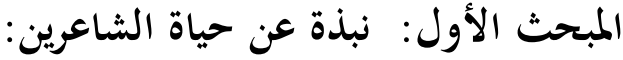 \\ المطلب الأول: تعريف موجز بالشاعرين:}

الشافعي، هو محمد بن إدريس الإمام: (150هـ - 204هـ)، هو إمام لمذهب فقهي، وقد شغّله الفقه بكامله، ولكنه

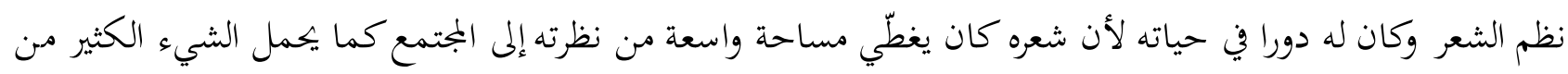
المواعظ والنصح والتوجيه، نشأ في حجر أمه في قلّة عيش وضيق حال. كان عالما بالقرآن والحديث والثفسير والعربية والعروض والنحو، وهو أوّل من دوّن علم أصول الفقه فكتب في ذلك " الرسالة "، لم يهتمّ الشافعي بالشعر كثيرا وقد قال في ذلك:

\section{ولو لا الشعر بالعلماء يزري لكنت اليوم أشعر من لبيب}

وعلى نقيض من أبي العتاهية، كان الإمام - يرممه الله - من أسخى الناس بما يجد، وقصص سخائه مشهورة(1). أما أبو العتاهية، أبو إسحاق إسماعيل بن القاسم بن سويد بن كيسان العنزي العيني (130هـ - 212هـ) يعدّ خير شاهد لشعر الزهد العربي في العصر العباسي الأول، الذي كان يعيش عيش المتهتكين وييري جرى أهل الخلاعة والمجون،

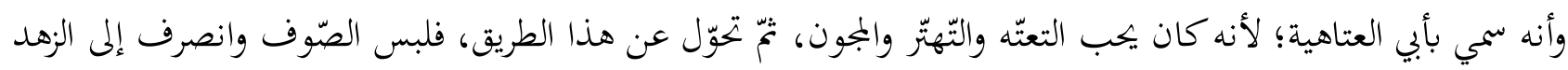

والتقشف (2)، لكن سلوكه تميّز بتناقض فاضح بين التظاهر بالزهد والدعوة إلى التجرّد وعمل البرّ، وبين البخل والشحّ (3). المطلب الثاني: أسباب نزعتهما الزهدية:

\section{الفرع الأول: العوامل الاجتماعية، الدينية، الثقافية والاقتصادية:}

إن حياة الإمام الشافعي الاجتماعية تشبه في كثير من النواحي حياة أبي العتاهية، من حيث كثرة الفرق والمذاهب الدينية والانحلال الأخلاقي وظهور البدع، وكان الإمام يرى أن الترابط الاجتماعي بين الناس أصبح ضعيفا، وإزاء هذا

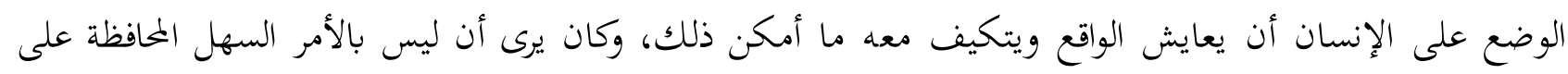
صديق ما لم تخفض جناحك وتغضي عن كثير من الأمور، وللشافعي في ذلك درس مطوّل ألقاه على يونس بن عبد

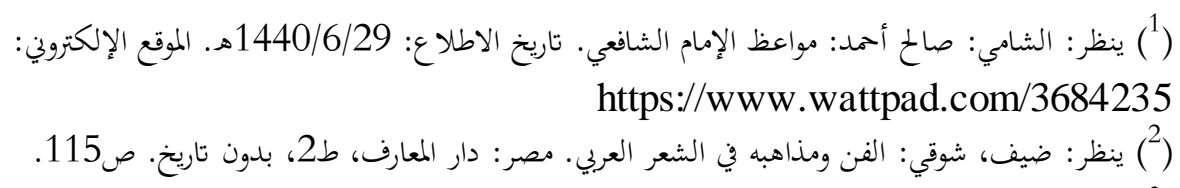

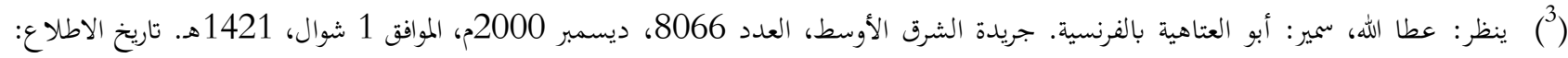
(1440/6/29هـ. الموقع الإلكتورني:

http://archive. aawsat.com/leader.asp?section=3\&artic le=19177\& issueno=8066\#.XIAW purAPIU available at: http://journal.uir.ac.id/index.php/THUMUHAT 2020 | السنة الثالثة، العدد الأول، أغسطس 
الأعلى، والإنسان الذي تحتاج إلى مداراته ليس بأخ لك وإرضاء الناس لا سبيل إليه، ولذلك فعليك بما ينفعك فالزمه، وبهذه الوصايا وغيرها يرشد الإمام إلى كيفية التعامل مع الناس، وهو لم يبخل بنصائحه في سبيل تبصير المسلم بكيفية أداء دوره في الحياة الاجتماعية بشكل فاعل (4) فالشافعي كإمام وفقيه لفت انتباهه هذه الانحرافات الحاصلة في عصره، فحرص على توجيه الناس بشتى الأساليب شعرًا ونثرًا.

مات أبو الإمام - رحهما الله - وهو صغير فحملته أمه إلى مكة وهو ابن سنتين لئلا يضيع نسبه، فنشأ بها وقرأ القرآن وهو ابن سبع سنين (5)، فهذا يعني أن أمّه قد أرضعته حب العلم والحرص على صحبة العلماء، ولم تصرفه عن ذلك لدنيا يصيبها أو حرفة يكتسب منها رغم يتمه وفقره. أما أبو العتاهية، فقد نشأ في بيئة كانت هناك طبقة تغرق في الترف والنعيم، وكان جمهور الشعب يعيش في الضّنك والبؤس، وظلت الحياة العقلية مزدهرة بما نقل وماكان ينقل من الثقافات الأجنبية، مما هيّأ لظهور فلاسفة عظام وعلماء بارعين في جميع العلوم اللغوية والبلاغية والنقدية والتاريخية والإسلامية والكلامية، وكثر حينئ النساك والزهاد في متاع الحياة الدنيا، وعاشوا معيشة كلها شظف وتقشف وتبتل وعبادة، ومن آثار الحركة العلمية في هذا العصر ظهور المذاهب الأربعة، المالكية والحنفية والشافعية والحنبلية، كما اتسم العصر الذي عاث فيه أبو العتاهية بالحرية الدينية، بحيث نرى فيه المذاهب المتعدّدة والفرق المتجدّدة والديانات السماوية، فلعل أبا العتاهية قد تأثّر بهذه الديانات والثقافات في مرحلة من حياته (6)

\section{كان في بدء أمه يبيع الجرار فقيل له (الجرار) ثم اتصل بالخلفاء وعلت مكانته عندهم (7).}

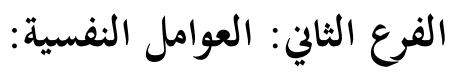
كانت حالات الإمام الشافعي النفسية واستعداداته الفطرية مختلفة عما سنراها عند أبي العتاهية، حيث اقتضت تربيته منذ صغره أن يختار هذا المذهب الزهدي.

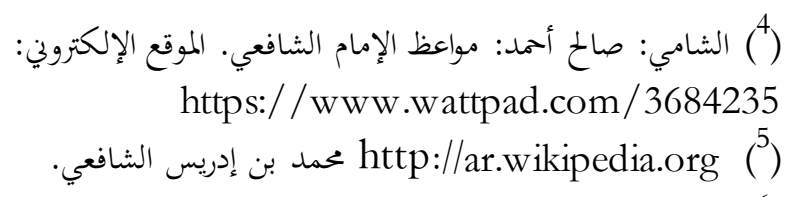
(6) ينظر: ضيف، شوقي: تاريخ الأدب العربي. مصر: دار المعارف، ط1، 1960-1995م. 80/3، 104/4، 505/3، 565، 5/4، 105/4، 
وإذا ما تتبّعنا ديوان الشافعي - رحمه الله - نجد أنه لم ينظم إلا في الأغراض التعليمية الدينية الحُّقية التوجيهية والإرشادية ولم ينظم فيما مضى من الأغراض التي ذكرناها لأبي العتاهية من مدح وغزل ورثاء وهجاء....إلخ، إنه لم ينصرف للدنيا قط؛ لأن طبيعة نشأته لم تكن لتفتح له فرصة الاغماك في ملذات الدنيا ، بل أعدّته ليكون حاملا همّ توجيه الناس وتعليمه ما ينفعهم في دنياهم وأخراهم، فكان واحدا من أولئك العلماء الذين يأمرون بالمعروف وينهون عن المنكر ويرون في ذلك من واجبات هذا الدين، فقيامه بنظم قصائد تحمل غاية زهدية إن هو إلا لسدّ باب حاجة في نفسه وهي مهمة الوعظ و تقديم النصيح للناس.

ومن الجوانب النفسية التي كانت تشغل بال الإمام وكان تأكيده عليها متكرّا: العقيدة والعلم وذكر الآخرة، هذا بالإضافة إلى تقديم ما ينفع الناس من النصح في دنياهم وأخراهم من النصح والإرشاد، كمدح القناعة وذم الطمع...

وتظهر لنا حياة أبي العتاهية في مظهرين متباينين: حياة الغزل ومعاقرة الخمر، وحياة الوعظ والتقشّف، فقد كان في

المرحلة الأولى من حياته يعيش كسائر شعراء عصره، يمدح ويرثي ويتغزّل، أشعاره في مدح الخلفاء العباسيين مثل (المهدي) و (الهادي) و (الرشيد)و (المأمون)، أما الغزل فتدلّ على انصرافه في أول عهده إلى حياة اللهو والتهتك، واشتهر بها حتى

زعموا أنه كني بأبي العتاهية لأنه كان يحب التهتك والمجون(9).

ولعل الدافع الأساسي في ترك سيرته الأولى هو فشله في حبّه لـ (عُتبة) جارية المهلدي (10)، فيقول المعربي في هذا الشأن:

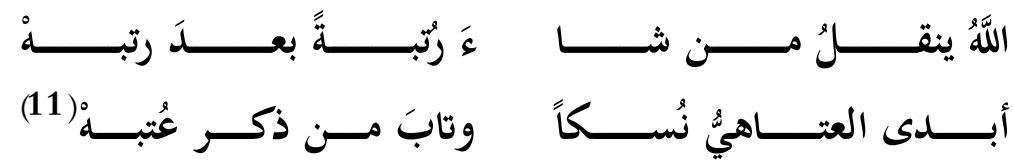

وهذا أبو العتاهية يشير إلى ما تحمّل من الألم والهجر في حبّ عتبة:

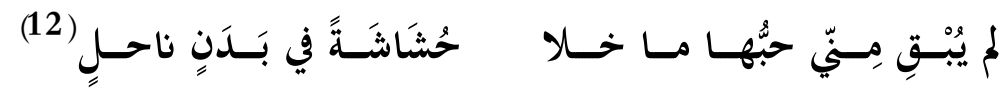

$$
\begin{aligned}
& \text { ( ) ينظر: الشافعي، محمد بن إدريس: ديوان الإمام الشافعي. جمعه وحققه وشرحه: الدكتور إميل بديع يعقوب. بيروت: دار الكتاب العربي، ط2، }
\end{aligned}
$$

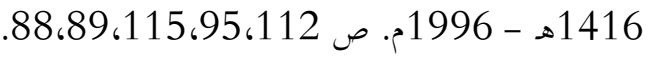

$$
\begin{aligned}
& \text { (9) (9نظر: ضيف، شوقي: تاريخ الأدب العربي. 240/3، } 249 . \\
& \text { 239/3. } \\
& \text { (11) المعري، أبو العلاء: شرح اللزوميات. تحقيق: سيدة حامد، زينب القوصى، منير المدني، وفاء الأعصر، إشراف: الدكتور: حسين نصار، مركز } \\
& \text { تحقيق التراث، بدون طبعة وتاريخ. 160/1. }
\end{aligned}
$$


إضافة إل ذلك، ربما إرادته التميزّ عن معاصريه الذين انغمسوا في اللهو واللعب، من العوامل التي أدت به إلى سلك هذا المذهب الزهدي في شعره.

المبحث الثاني: تحليل المضامين الزهدية في شعر الإمام الشافعي، وأبي العتاهية: أولا: قصيدة الإمام الثافعي:

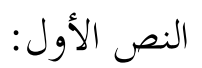

وطــبـ نفســاً إذا حكـــــ القضــــــ

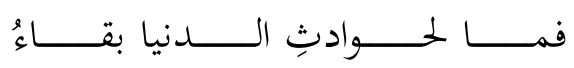

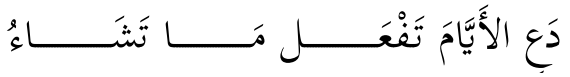

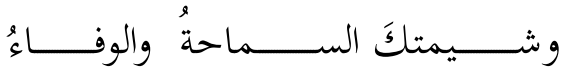

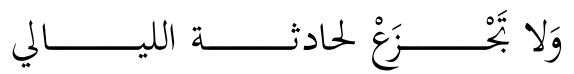

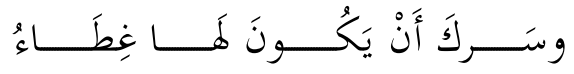

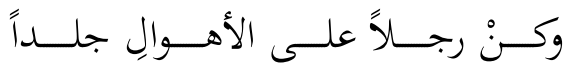

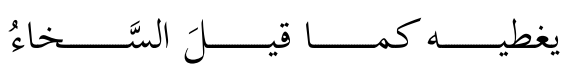

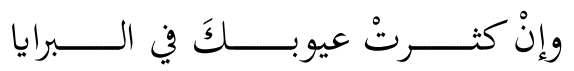

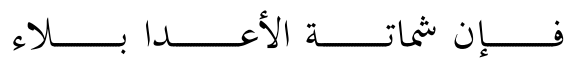

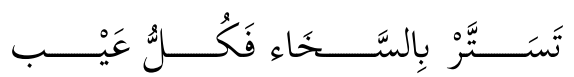

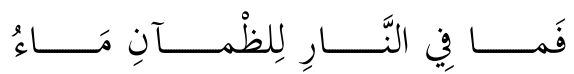

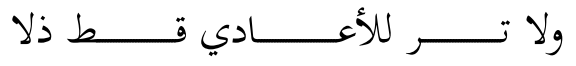

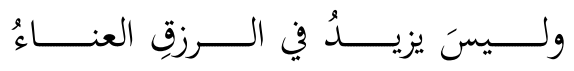

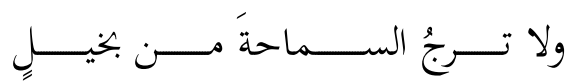

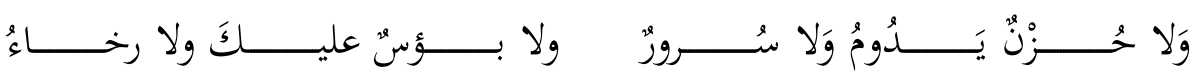

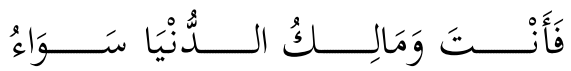

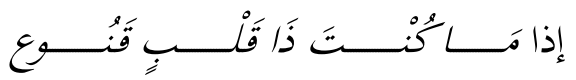

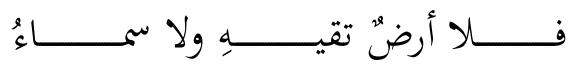

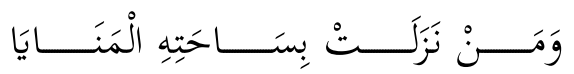

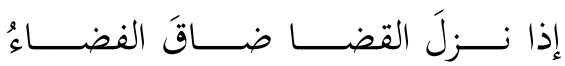

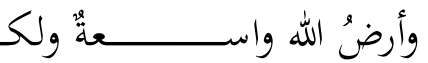

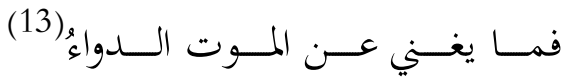

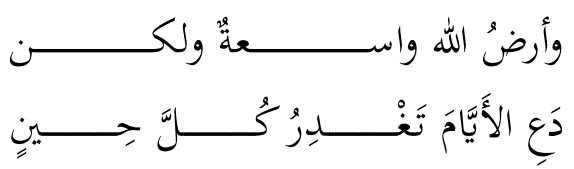

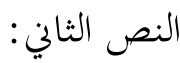

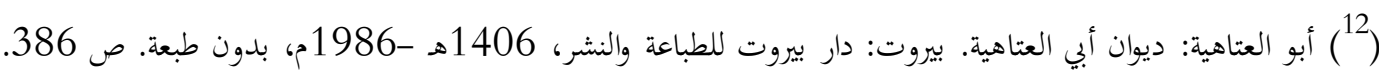

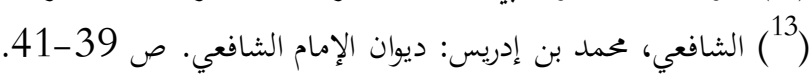




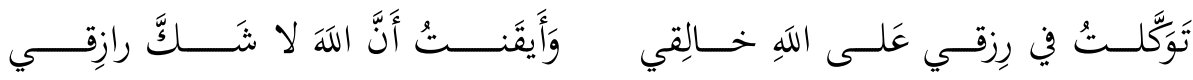

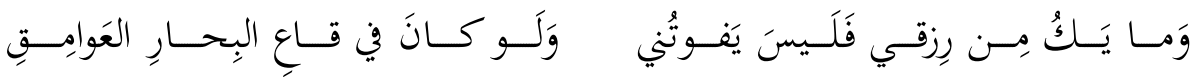

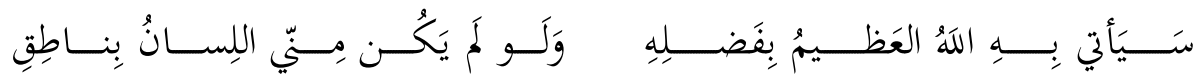

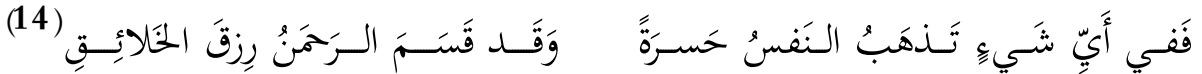

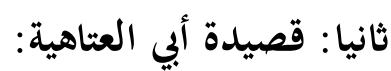

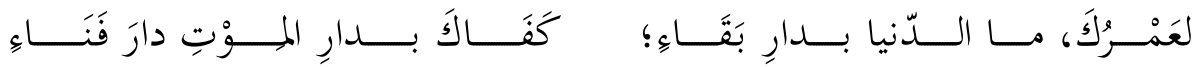

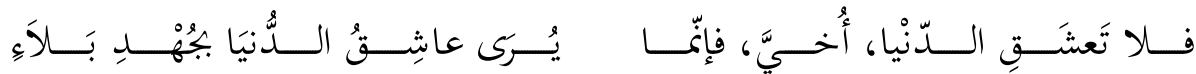

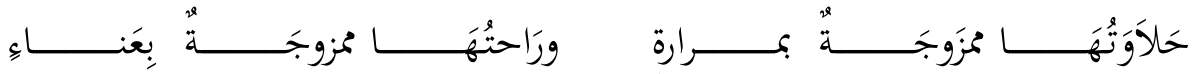

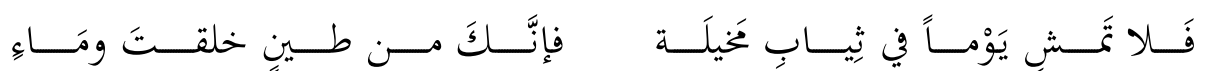

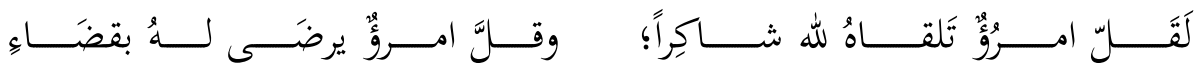

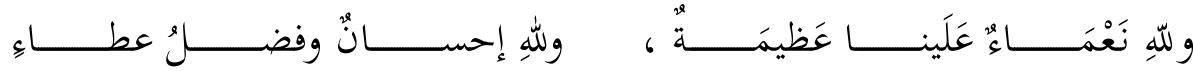

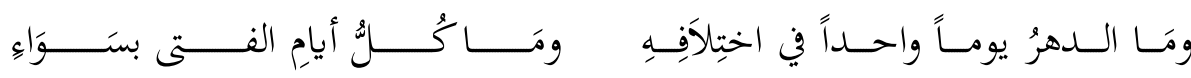

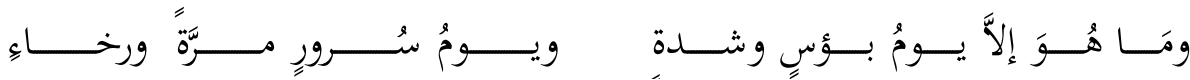

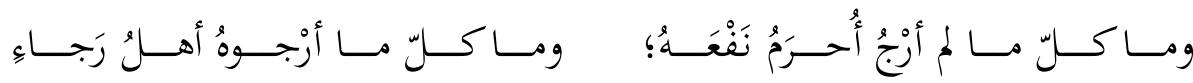

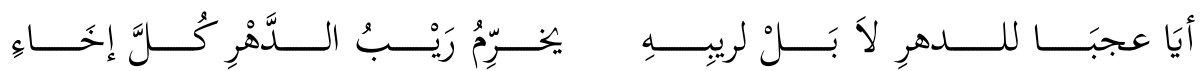

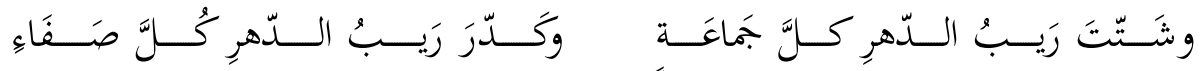

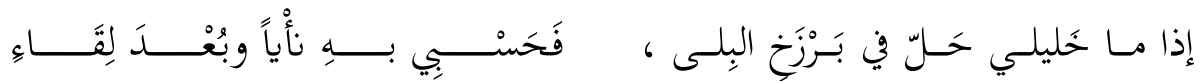

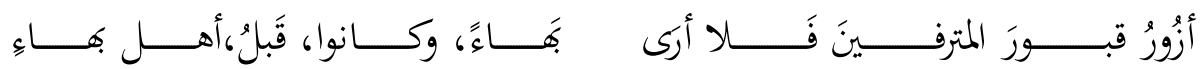

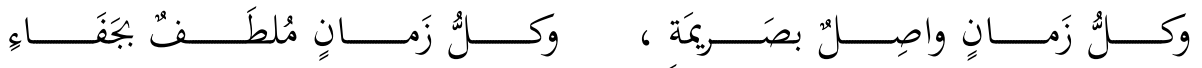

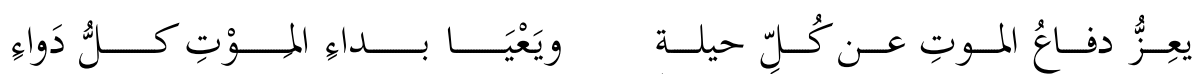

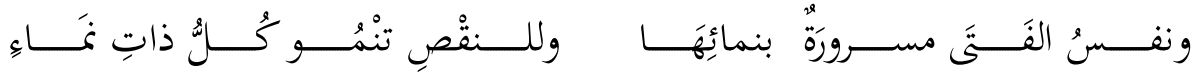

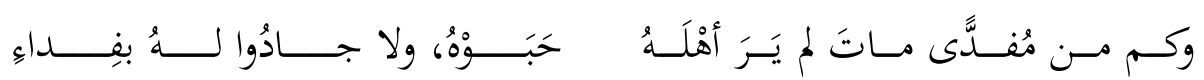

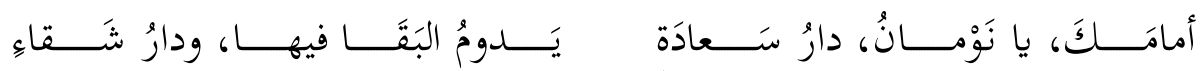

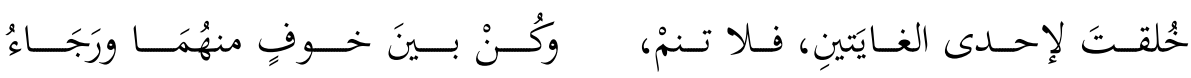

$$
\text { (المصدر السابق. ص } 109 .
$$


(15)

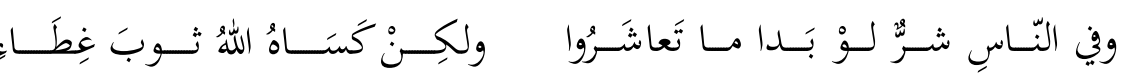

ثانيا: ملامح تأثّرّ أبي العتاهية بالإمام الشافعي:

1- لقد بلغ صيت الإمام الشافعي من فرط الذيوع ما بلغ ، قال أيوب أبو يعقوب البويطي: رأيت الناس بمصر والشام والعراق والكوفة والبصرة والحجاز من كل صنف من علماء القرآن والفقه ولسان العرب والسير والكلام وأيام العرب، ما رأيت أحداً يشبه الشافعي(16)، هذا يعني أن الإمام كان معروفا في كل هذه الأقطار المذكورة وإذا كان أبو العتاهية قد قضى شطرا من حياته في الكوفة، فلا شك أنه سمع بالإمام أو اطلع على كتبه، إذكان يجيد اللغة العربية.

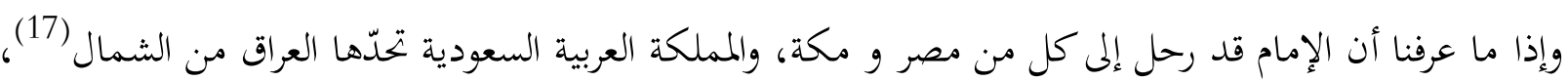
وقد انتقل أبو العتاهية بين مدن العراق، حيث ولد في عين التمر تم انتقل إلى الكوفة فبغداد، كل ذلك يؤَّد أنه كان قريبا من الإمام، وسماعه منه، ومن تَّمّ تأثيره به. ولنذهب إلى أبعد من ذلك، فقد رحل الإمام إلى العراق أكثر من مرة يقول صاحب البداية والنهاية: "ثم عاد الشافعي إلى العراق في سنة خمس وتسعين ومائة فاجتمع به جماعة من العلماء هذه المرة منهم أحمد بن حنبل وأبو ثور

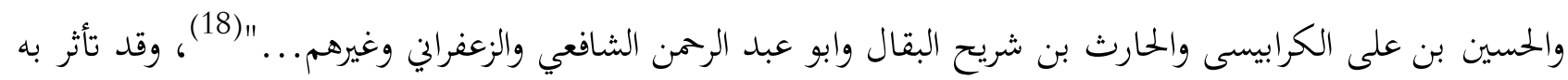
علماء كثيرون منهم أبو ثور إبراهيم بن خالد بن أبي اليمان الكلبي يقول صاحب كتاب (تاريخ ابن الوردي): "... فيها توفي أبو ثور إبراهيم بن خالد بن أبي اليمان الكلبي الفقيه البغدادي صاحب الإمام الشافعي وناقل أقواله القديمة عنه وكان على مذهب أهل الرأي حتى قدم الشافعي إلى العراق فاتبعه..."(19). كل هذا يؤيّد قولنا بتأثّر أبي العتاهية به.

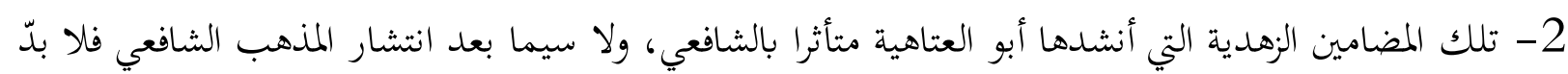
أن يكون أبو العتاهية بثقافته العربية الواسعة قد طالعه مرارًا وتكرارًا، ومن أبرز تلك المضامين:

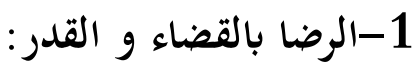
يقول الشافعي:

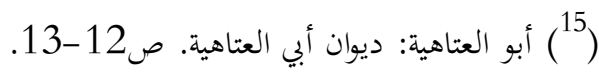
(16) اليحصبي، أبو الفضل القاضي عياض: ترتيب المدارك وتقريب المسالك. المغرب: مطبعة فضالة - المحمدية، ط13، 1966-1970.185/3. 185/

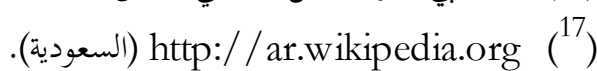

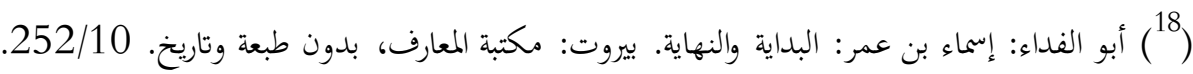

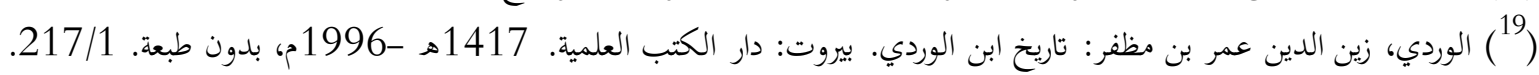



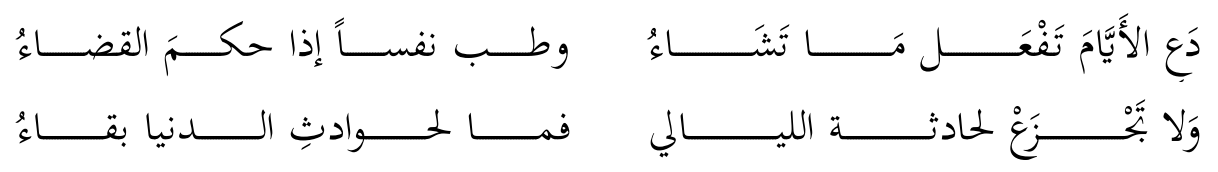

يشير الإمام في هذين البيتين إلى أنه لا بد من التسليم والإيمان بالقضاء والقدر، وأن مصائب الليالي ونوائبها الليالي، سوف تزول فلا بقاء لما، وهي سنة الله في أرضه. وقد وظّف أبو العتاهية معنى القضاء بشكل مشابه لهذا، حيث بدأ بذمّ الدنيا، في قوله:

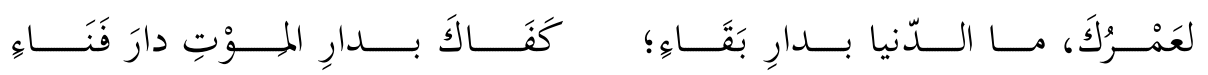

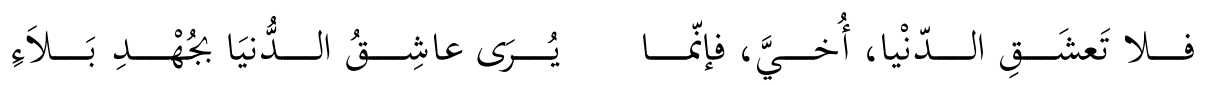

فعاشق الدنيا لا يخلو عن مصائب، فكأمّا استخدم صيغة التصغير في لفظة (أخي) للتقليل من شأن عاشق الدنيا. و لعلّ غرض الشاعر من هذه المقدمة، التي صاغها لذم الدنيا، هو هميئة ذهن المخاطب لاستيعاب معنى القضاء والقدر، فالمرء عندما يكره شيئا، فإنه لا يبالي بما يجري فيه من خير أو شرّ، ولا يبدي له اهتمامًا.

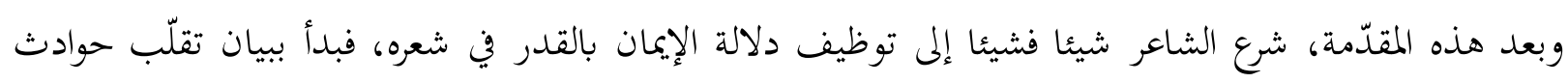

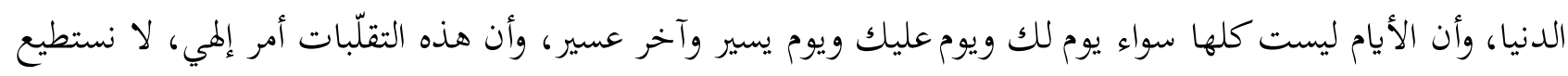
تغييرها، بل علينا الإيمان بقضاء الله وقدره، يقول:

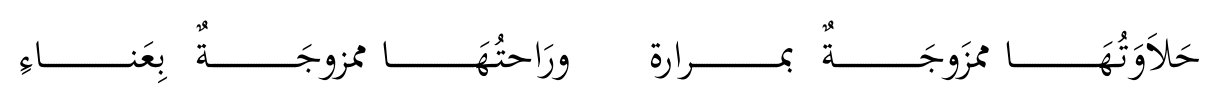

$$
\text { ويقول أيضا: }
$$

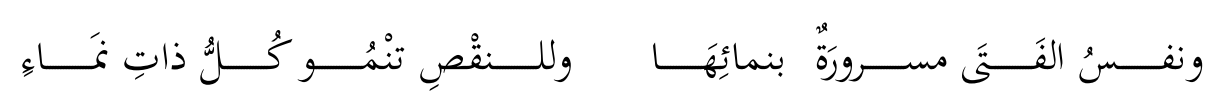

فالعمر كلما ازداد نقص، وما خُحُقنا للبقاء، بل ثمة يوم آخر غير اليوم: (فما لحوادث الدنيا بقاء)، ويؤكد هذا المعنى

$$
\text { في أبيات أخرى، حيث يقول: }
$$




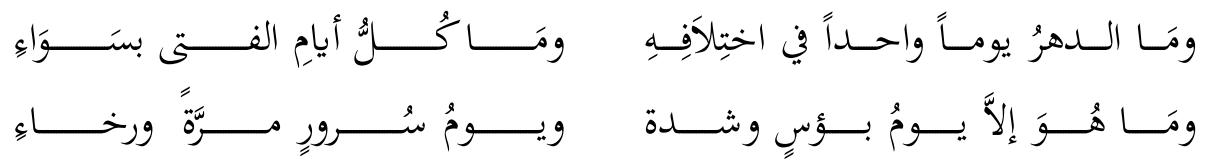

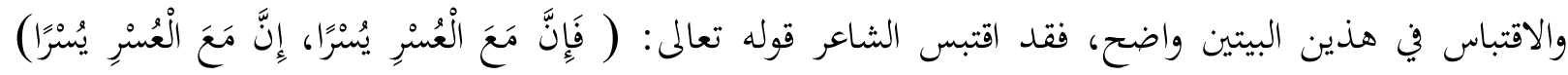

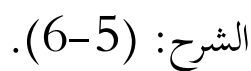

ثم يصرّح بضرورة الرضا بقضاء الله وقدره، وشكره على ما أسبغ علينا من نعمه وعدم الكفران بها، فيقول:

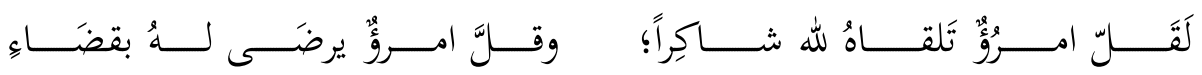

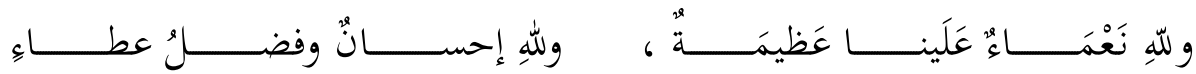

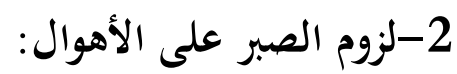

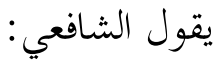

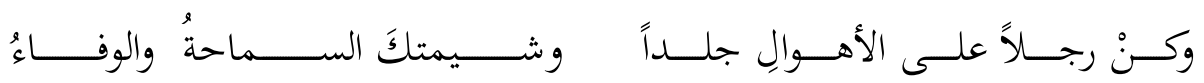

يطالب الشاعر المرء في صدر البيت أن يكون قويا صلدا أمام الشدائد، ولعلّ الغرض من تخصيص الشاعر الرجل بالخطاب دون المرأة، كون صفة القوة والتصلّد تكمن في الرجال أكثر من النساء. ويشير أبو العتاهية إلى المضمون نفسه، فيقول:

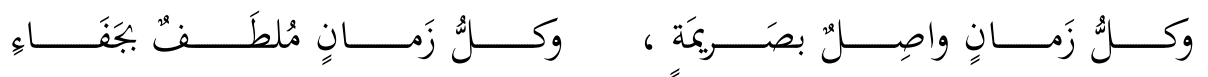

فالزمان محفوف بالجدّ والصعاب، وما حُلق الإنسان للرّاحة (لَقَدْ حَلَقْنَا الْإِنْسَانَ فِي كَبَدِ)؛؛ لذا عليه أن يستعدّ لمواجهة تلك الصعاب بالصبر والسماحة. 3-الرزق بيد الله:

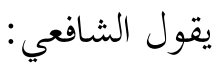

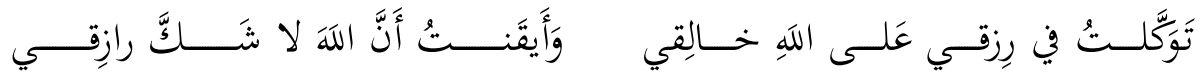




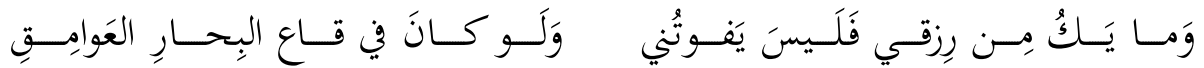

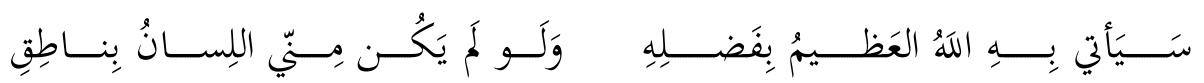

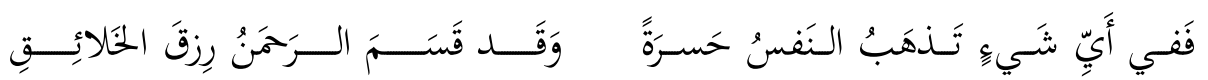
فالرزق بيد الله، ولا يفوت المرء ما قد كتبه الله له ، وإن كان في قاع البحر، يأت به الله. ويقول الشافعي أيضا:

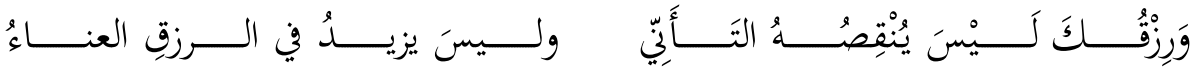

فالتمهل في طلب الرزق لا ينقصه، وكذلك التعب في السعي - لحدّ ارتكاب المخظور - لا يزيده، وإذا كان الأمر كذلك، فليس للمرء إلا أن يقنع بما قدره الله له، لأن القناعة من أجلّ ما يملك الإنسان في الحياة، يقول الشافعي:

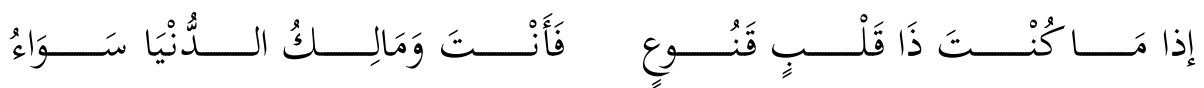
تم يشرع الشاعر في ذكر فضائل السخاء، وذّمّ البخل حيث يقول:

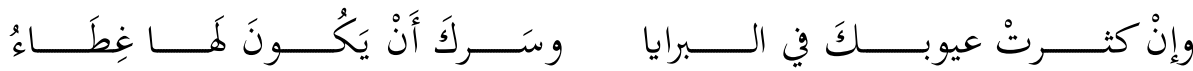

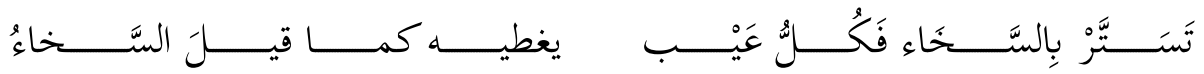
فبالجود والكرم يستطيع المرء إخفاء عيوبه على أعدائه، والناس كافة.

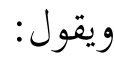

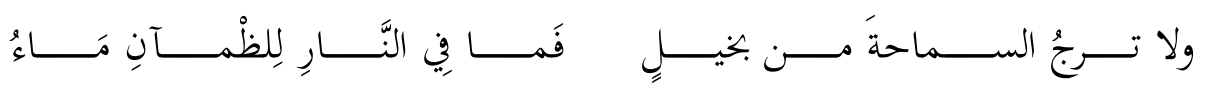
يحاول الشاعر -عن طريق المقارنة بين السخاء والبخل- الإشارة إلى أن الرزق بيد الله، فالسخاء مطلوب دائما وأبدا ما دام البخل لن يزيد في الرزق شيئا، كما أن السخاء لن ينقصه كذلك. ولأبي العتاهية بيت يُجمل المعنى نفسه، حيث يقول: 


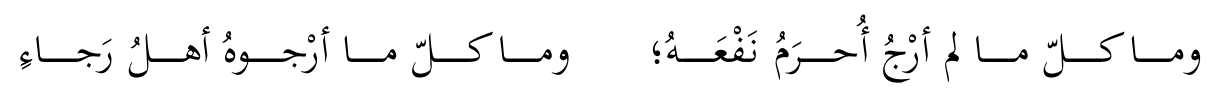

فالرزق لا ينقص بالتأني وعدم الطلب، كما أن التفنّن في طلبه بدرجة الوقوع في الحرام لا يزيده شيئا، بل على الإنسان أن يقنع بما لديه لأن الله جعل لكل شيء قدرا. 4-ذكر الموت:

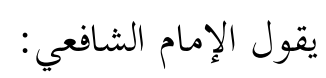

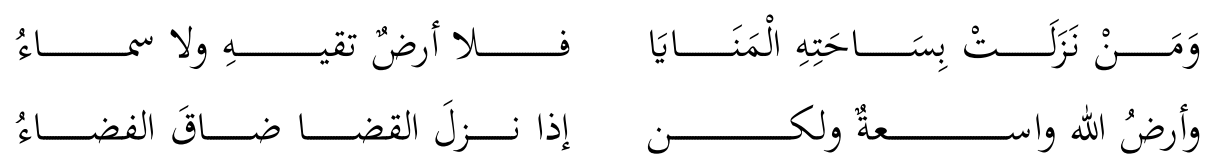

فالأرض الفسيحة تضيق إذا نزل القضاء، وما حكم الله للإنسان. ثم ذكر خيانة الأيام وأها لن تُسخر لأحد، وأن الموت لا يغني عنه دواء طبيب، فقال:

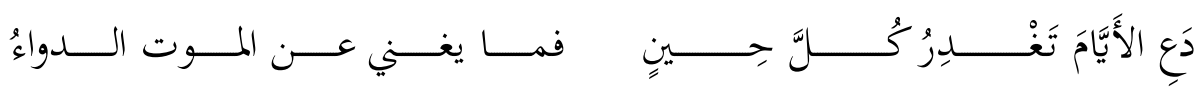
ونجد أبا العتاهية، يصوغ المعنى نفسه، فقد استغرق في ذمّ الدنيا، ونظر إليها نظرة ازدراء وتشاؤم واحتقار، كل ذلك لألّا يلتفت إليها المرء، ويكدّر بها آخرته، وينسى الموت، فيقول:

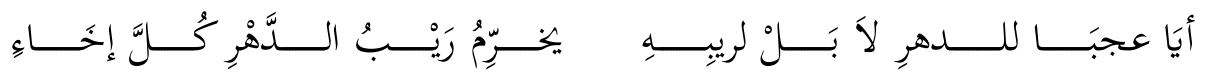

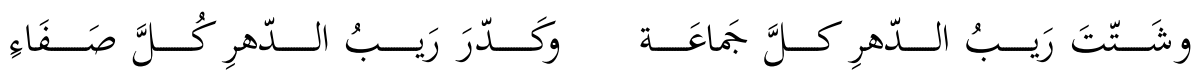

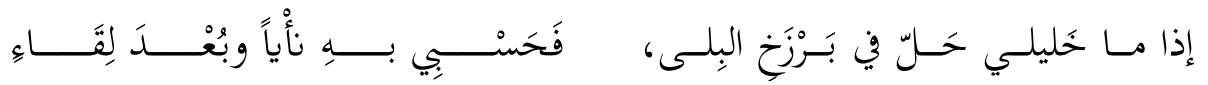

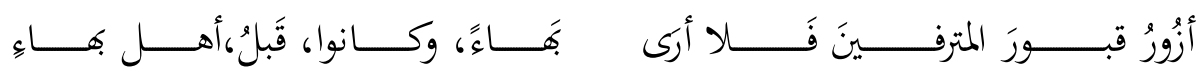

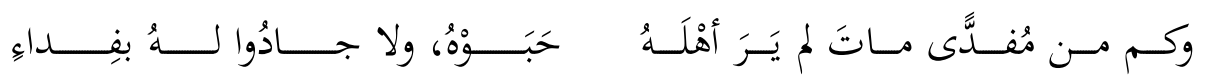

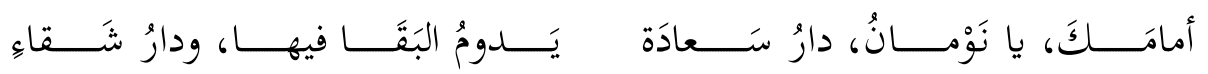

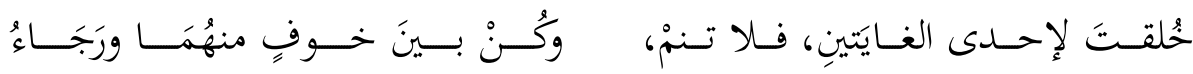




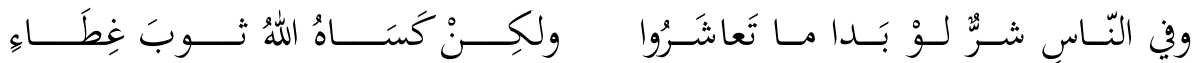

ولعلّ المقصود بكلمة (الثرّ) في البيت الأخير، هو السرّ الذي يبقيه الله -سرمدا- بين الميت وأهله، فلميت لا الا يدري ماذا يجري وراءه، وكذلك الأحياء لا يدون ماذا يحدث لميتهم. تلك هي المضامين المشتركة في هاتين القصيدتين وقد رأينا كيف تأثر أبو العتاهية ببعض مضامين الشافعي الزهدية، لكنه ألبسها لبوسه الخاص، لذا فهي بعيدة كل البعد عن السرقات الأدبية أو الاقتباس التام، وقريبة إلى التوارد الذهني والتأثّر.

ثالثا: الأساليب الشعرية لمذين الثاعرين:

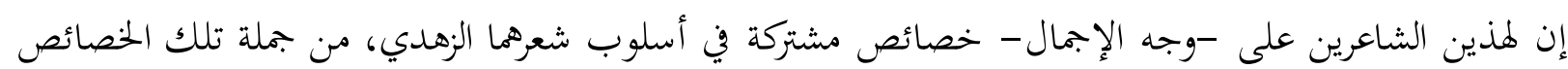

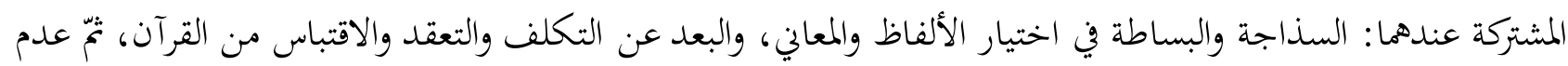
التفنّن في استخدام الصور البلاغية.

المنهج

يجب أن تجعل المواد والأساليب القراء قادرين على إعادة إنتاج التجربة. قدم تفاصيل كافية للسماح بإعادة إنتاج العمل.

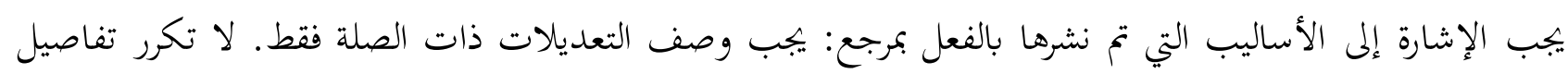

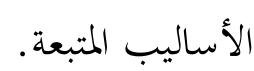
تحديد الأقسام الفرعية

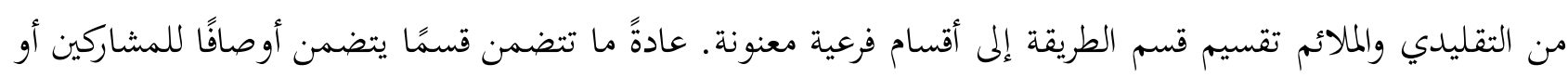

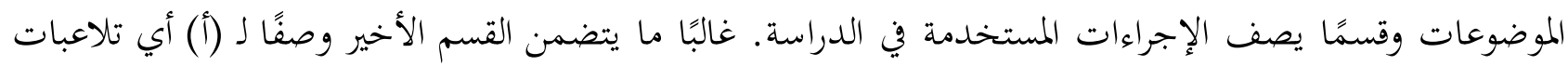

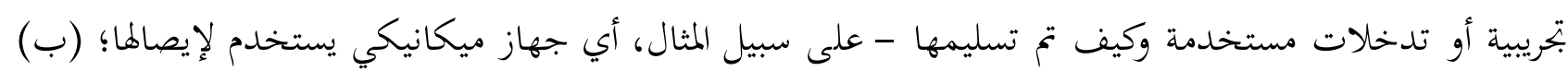

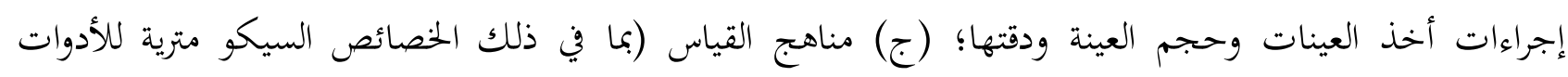

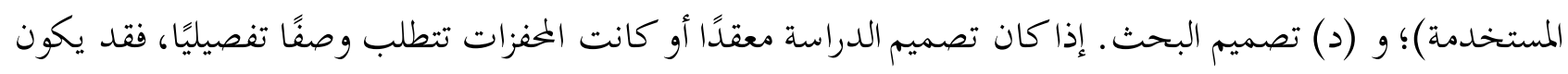

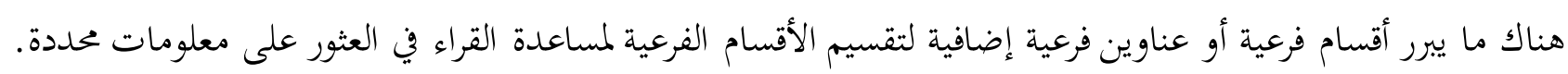

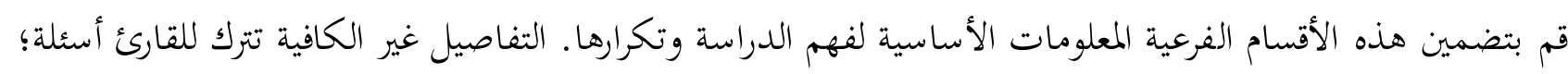

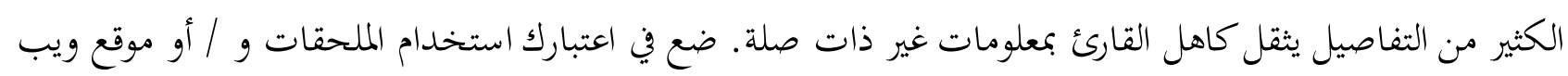
تكميلي للحصول على معلومات أكثر تفصيلاً. خصائص المشارك (الموضوع) التحديد المناسب للمشاركين في البحث أمر بالغ الأهمية لعلم وممارسة علم النفس، لا سيما

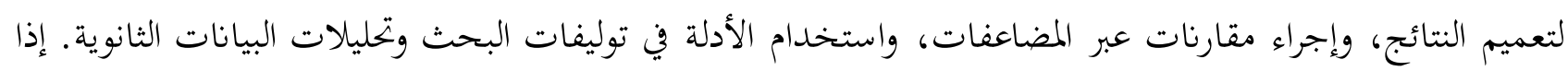


شارك البشر في الدراسة، فقم بالإبلاغ عن معايير الأهلية والاستبعاد، بما في ذلك أي قيود تستند إلى الخصائص الديموغرافية.

\section{تصميم البحث}

حدد تصميم البحث في قسم الطريقة. هل تم وضع الأشخاص في ظروف تم التلاعب بها، أم تمت ملاحظتهم بشكل

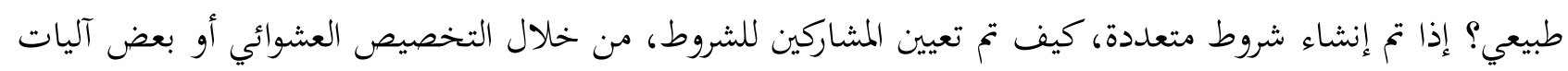

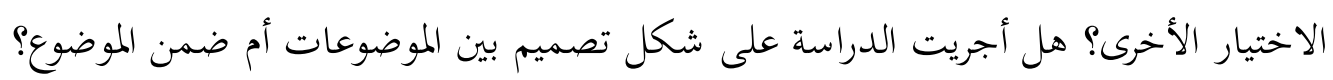

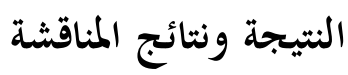

يجب أن تكون واضحة وموجزة. يجب أن تلخص النتائج (العلمية) بدلاً من تقديم البيانات بتفصيل كبير . يرجى إبراز

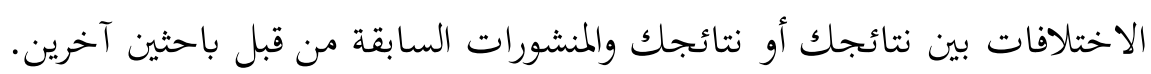

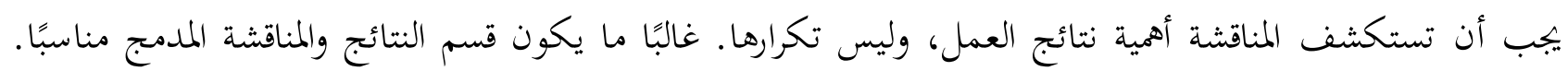
تجنب الاستشهادات الواسعة ومناقشة الأدبيات المنشورة.

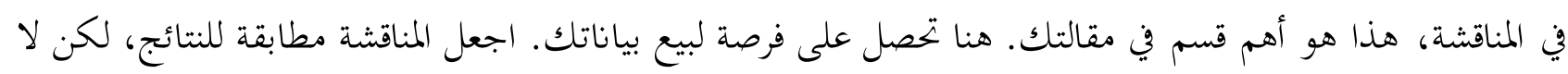

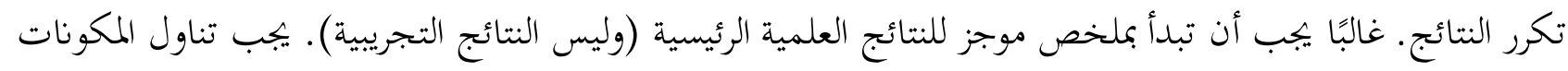

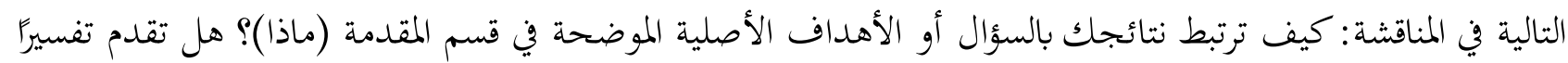

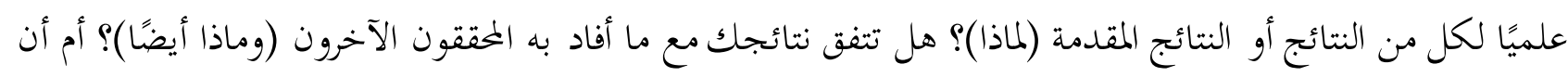
هناك اختلافات؟ بعد تقديم النتائج، ستكون في وضع يسمح لك بتقييم وتفسير آثارها، خاصة فيما يتعلق بفرضياتك الأصلية. هنا ستقوم

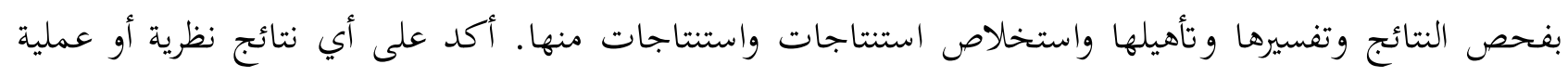

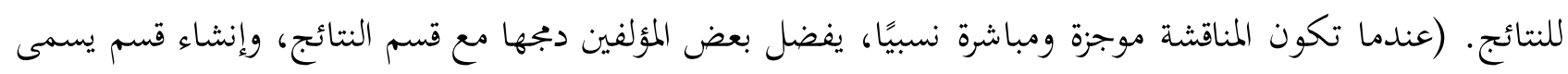

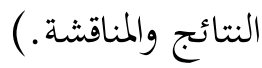
افتح قسم المناقشة ببيان واضح للدعم أو عدم الدعم لفرضياتك الأصلية، ميزة الفرضيات الأولية والثانوية. إذا لم يتم دعم

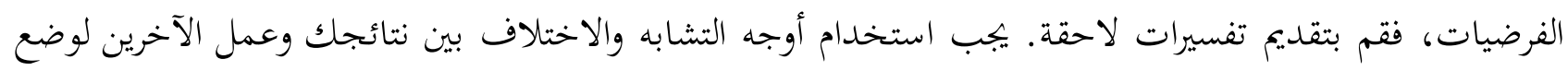

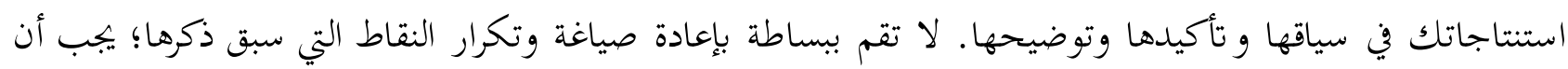
يساهم كل بيان جديد في تفسيرك وفهم القارئ للمشكلة.

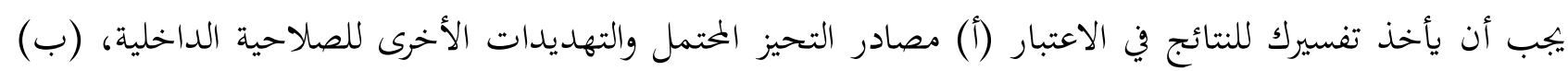

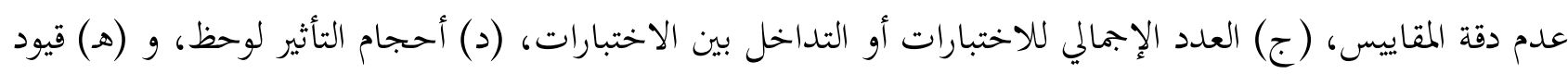

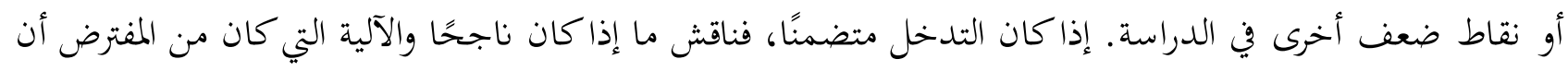

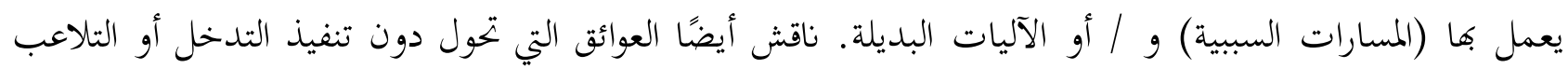


بالإضافة إلى الدقة التي تم بها تنفيذ التدخل أو التلاعب في الدراسة، أي أي اختلافات بين التلاعب كما هو مخطط له وكما تم تنفيذه. اعترف بالقيود المفروضة على بحثك، وتناول التفسيرات البديلة للنتائج. ناقش التعميم أو الصلاحية الخارجية للنتائج. يجب أن يأخذ هذا التحليل النقدي في الاعتبار الاختلافات بين السكان المستهدفين والعينة التي يتم الوصول إليها. بالنسبة للتدخلات، ناقش الخصائص التي تجعلها أكثر أو أقل قابلية للتطبيق على الظروف غير المدرجة في الدراسة، وكيف وماهية النتائج التي تم قياسها (بالنسبة إلى المقاييس الأخرى التي ربما تم استخدامها)، وطول الفترة الزمنية للقياس (بين هاية التدخل وقياس النتائج)، والحوافز ، ومعدلات الامتثال ، والأوضاع المحددة المشاركة في الدراسة فضلا عن القضايا السياقية الأخرى.

أنهِ قسم المناقشة بتعليق منطقي ومبرر حول أهمية النتائج التي توصلت إليها. قد يكون هذا القسم الختامي موجزًا أو

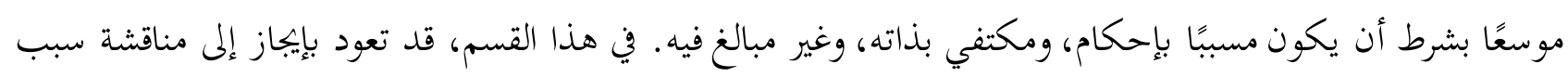

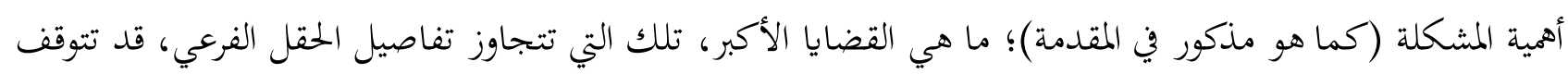
على النتائج؛ وما هي المقترحات التي تم تأكيدها أو عدم تأكيدها من خلال استقراء هذه النتائج لمثل هذه القضايا الشاملة.

الحاتمة

يجب أن تستجيب الاستنتاجات لأهداف البحث. يخبرنا كيف يتقدم عملك بالمجال من حالة المعرفة الحالية. بدون

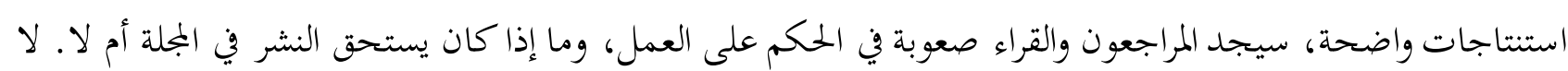
تكرر الملخص، أو تسرد النتائج التجريبية فقط. قدم مبررًا علميًا واضخًا لعملك، وحدد التطبيقات والإضافات الممكنة. يجب عليك أيضًا اقتراح تجارب مستقبلية و / أو الإشارة إلى التجارب الجارية.

المراجع

Chaer, Abdul. Linguistik Umum. Jakarta: Rineka Cipta, 2003. ŁBook

Boudelaa, Sami. and William D Marslen-Wilson. "Aralex: A Lexical Database For Modern Standard Arabic, "Behavior Research Methods, Vol. 42, No. 2, 2010. «Journal

Clancey, W.J. "Communication, Simulation, and In-telligent Agents:

Implications of Personal Intelligent Machines for Medical Education".

In Proceedings of the Eighth International Joint Conference on Artificial Intelligence, 2011, 556-560. ŁConference Proceeding.

Rice, J. "Poligon: A System for Parallel Problem Solving", Technical 
Report, KSL-86-19, Dept. of Computer Science, Stanford Univ, 2014. $\leftarrow$ Report

Clancey, W.J. "Transfer of Rule-Based Expertise through a Tutorial Dialogue". PhD Dissertation, Department of Computer Science, Stanford University, 2013. $\leftarrow$ Thesis

Ivey, K.C. Citing Internet sources URL http://www.eeialex.com/eye/utw/ 96aug. html. (2 September 2012) $\leftarrow$ Website 